\begin{tabular}{|c|l|}
\hline Title & Reflective leadership and team learning : an exploratory study \\
\hline Author(s) & Matsuo, Makoto \\
\hline Citation & $\begin{array}{l}\text { Journal of Workplace Learning, 28(5), 307-321 } \\
\text { https:/doi.org/L0.1108/JWL-12-2015-0089 }\end{array}$ \\
\hline Issue Date & 2016 \\
\hline Doc URL & http://hdl.handle.net/2115/72132 \\
\hline Type & article(author version) \\
\hline File Information & Self-archiving_(Matsuo_2016)JWL.pdf \\
\hline
\end{tabular}

Instructions for use 


\title{
Reflective leadership and team learning: an exploratory study
}

\author{
Makoto Matsuo \\ Hokkaido University, Sapporo, Japan
}

\begin{abstract}
Purpose - Although the relationship between leadership behaviors and team reflexivity has been investigated in prior research, little is known about the dimensions of reflective leadership or leadership behaviors that facilitate reflection in a group or organization. This paper aims to examine the interrelated characteristics of reflective leadership behaviors that promote team learning using survey data.

Design/methodology/approach - Because this research was exploratory in nature, a research model was developed based on the preliminary research. The research model was tested using a quantitative study of 507 employees in 98 teams.

Findings - Results of regression analyses of a group-level study revealed three types of reflective leadership - open reflection, problem-based reflection and goal-based reflection - and found that only the open reflection and goal-based reflection were positively related to team learning.
\end{abstract}

Research limitations/implications - As reflective leadership has not been examined in previous studies, the research model and the measurement scales were developed based on preliminary research in the present research.

Practical implications - Team leaders need to understand that goal-based reflection plays a central role in reflecting on their work because it may provide members with criteria to recognize whether they are on the right track.

Originality/value - The present research revealed three dimensions of reflective leadership that had not been adequately investigated previously.

Keywords Reflection, Team learning, Reflexivity, Reflective leadership

Paper type Research paper 


\section{Introduction}

It is the growing recognition that workplace learning is seen as a key medium by which experiential and contextual knowledge can be generated and shared (Clarke, 2006). In promoting learning and performance in the workplace, reflection or reflexivity has a critical role both at the individual and group levels (Boud et al., 2006; Kolb, 1984; Schön, 1983; West, 1996). Previous studies have found that team reflexivity is positively associated with new product success (Dayan and Basarir, 2010; Lee, 2008), team effectiveness (Hoegl and Parboteeah, 2006), team innovation (Somech, 2006) and team functioning (van Ginkel et al., 2009).

In searching for the antecedents of reflexivity, some studies found that facilitative and transformational leadership promoted team reflexivity (Carmeli et al., 2013; Hirst et al., 2004; Schippers et al., 2008). These studies indicate the importance of manager's and team leader's roles in guiding reflexive dialog in the workplace. However, how managers or leaders specifically facilitate reflection in teams was not sufficiently substantiated. In the absence of a focus on how leadership behaviors enhance reflection or reflexivity within a team in more detail, it is unlikely to identify the mechanisms

The main goals of the present research were:

- to explore the dimensions of reflective leadership, i.e. the leadership behaviors that promote reflection in a group or organization; and

- to examine their relationship with team learning using qualitative and quantitative data.

In analyzing the characteristics of reflective leadership, I focused on leaders' behaviors in facilitating reflection at regular meetings because work progress is often monitored and discussed in such review meetings. In this study, reflection refers to stepping back to ponder the meaning of experiences, whereas reflexivity is defined as the extent to which an individual overtly reflects on his or her experiences.

The present research differs from previous works in the following two ways. First, reflective leadership was investigated in an exploratory way. Specifically, the measurement scales for reflective leadership were developed by using a methodology: in addition to traditional quantitative surveys, an open-ended survey with qualitative interviews was also adopted. Second, this study focused on leadership behaviors to promote not only transformation or facilitation but also reflection or reflexivity in the workplace. By investigating the role of reflective leadership, it may make us able to further ascertain the process of team learning.

The article is organized as follows. First, the literature on team learning, reflection, 
reflexivity and leadership is reviewed. Next, research questions are proposed based on the literature review. Then, the qualitative and quantitative methods used to address these questions are presented. Finally, results are presented and discussed from theoretical and practical viewpoints.

\section{Theoretical background}

In this section, I begin by reviewing literature on the characteristics of reflection at the individual level. Then, the conceptual and empirical studies related to team reflexivity and leadership are examined. Finally, I define the concept of team learning based on previous research.

\section{Learning and reflection}

Past research indicated that about 70 per cent of a manager's development resulted from challenging work experiences (Lombardo and Eichinger, 2010). In explaining how people learn from their experiences, Kolb (1984) suggested a cyclical model which constitutes four stages: concrete experience, reflective observation, abstract conceptualization and active experimentation. This model describes that immediate personal experience is the fundamental for observation and reflection, which subsequently lead to develop abstract hypotheses or concepts. Afterwards, these hypotheses or concepts provide guidance for learners to create new experiences. The model suggests that reflective activities are necessary and critical components in the experiential learning process (DeFillippi, 2001) and provide a foundation for transformation of an individual's theory-in-use (Enoch, 1997).

According to Boud et al. (2006), reflection, defined as the practice of "periodically stepping back to ponder the meaning of what has recently transpired to ourselves and to others in our immediate environment" (Raelin, 2002, p. 66), is a key to learning to improve production and to making life at work more satisfying. Prior researchers have focused on reflection as strategically important in the initial and continuing development of professionals (Chivers, 2003).

With regard to the type of reflection, Kember et al. (2000) classified reflection into four hierarchical levels:

(1) habitual action (activities being conducted automatically or with minimum conscious thought);

(2) understanding (comprehension of a concept without reflecting upon its significance in personal or practical situations);

(3) reflection (internally examining and exploring an issue of concern, triggered 
by an experience); and

(4) intensive reflection (a higher level of reflective thinking through which can be transformed our meaning framework).

Using Kember et al.'s (2000) framework, Peltier et al. (2005) conducted a survey of MBA students and found that reflection and intensive reflection were positively related to program outcomes; in contrary, habitual action and understanding were negatively related to these outcomes. Intensive reflection, often described as critical reflection, entails challenging the validity of presuppositions in prior learning and examining the taken-for-granted context within which the task or problem is situated. (Mezirow, 1990; Reynolds, 1998). Based on this notion, Cunliffe (2009) proposed the concept of a "philosopher leader" who thinks more critically and reflexively about the group, their actions and the situations in which they find themselves.

On the other hand, Schön (1983) distinguished reflection-on-action from reflection-in-action. The former entails ex post facto reflection in which one leans back and consider matters at hand, whereas the latter refers to reflection focusing on the immediacy of practice (Yanow, 2009). Reflection-in-action consists of on-the-spot efforts to surface, criticize, restructure and to test intuitive understandings of experienced phenomena; often, it takes the form of a reflective conversation with the situation (Schön, 1983).

\section{Team reflexivity and leadership}

As conditions for productive reflection, Cressey et al. (2006) pointed out the following features:

- collective, rather than individual, orientation;

- contextualization within work;

- involvement of multiple stakeholders;

- a generative rather than instrumental focus; and

- a developmental character.

This suggests that collective reflection within a team at work can provide significant opportunities for learning and development.

Regarding the question of whether reflexivity is a team-level phenomenon or simply an attribute of individuals within the team, West (2000) argued that it is a property of individual team members; yet, the aggregated reflexivity of individuals may well contribute to team reflexivity, in which case, team task reflexivity should be 
conceptualized as a team-level phenomenon. Specifically, team reflexivity was defined as "the extent to which group members overtly reflect on and communicate about the group's objectives, strategies, and processes and adapt these to current or anticipated circumstances” (West, 1996, p. 559). Hoegl and Parboteeah (2006) mentioned that team reflexivity is based on the notion that a team's environment is ever changing, and that there is a need for constant reflection and contemplation to assess the most current environment so as to apply the best action.

One key situational factor that enhances reflection and reflexivity in the team is leadership. Edmondson (2003) argued that reflection is an essential part of the team learning process and that a team leader's behaviors influence the reflective practices of the team. Some studies have reported a positive relationship between team leadership and team reflexivity. For example, Hirst et al. (2004) found that facilitative leadership was associated with team reflexivity. In their study, the facilitative leader promoted respect and positive relationships among team members, productive conflict resolution and open expression of ideas and opinions. Schippers et al. (2008) reported that a team leader's transformational leadership enhanced team reflexivity and performance through engendering a shared vision within the team. They noted that sharing the vision made it easier for the team to reflect on whether the team was still on the right path as well as on alternative ways forward. Carmeli et al. (2013) also found that transformational leadership facilitated the development of employees' creative problem-solving capacity by shaping a climate of psychological safety conducive to reflexive processes. These studies suggested that leadership plays a critical role in ensuring psychological safety by creating an atmosphere where members can express their ideas and opinions openly, and in promoting shared visions within a team.

\section{Team learning}

It is important to clarify the meaning of team learning in this study. According to Marsick and Watkins (1990), learning is conceptualized as the way in which individuals or groups acquire, interpret, reorganize, change or assimilate clusters of related information, skills and feelings (p. 4). However, there are two different perspectives of learning: "learning processes" and "learning outcomes”. Regarding learning processes, Edmondson (1999) defined "team learning behavior" as an ongoing process of reflection and action, characterized by asking questions, seeking feedback, experimenting, reflecting on results and discussing errors or unexpected outcomes. In contrast, being distinguished from learning process, "learning outcomes" refers to adaptation to change, greater understanding or improved performance in teams. For 
example, Zellmer-Bruhn and Gibson (2006) conceptualized team learning as the extent to which a team created new processes and practices.

Of the two perspectives, the present research adopted learning outcome perspective in defining team learning as staff development, the introduction of new work processes, process improvement and task performance. This conceptualization corresponds to previous literature that defined team learning as skill development of individual members (Clarke, 2005; Fenwick, 2008), and as creation of new collective work processes (Zellmer-Bruhn and Gibson, 2006). The present research also included "quality of team performance" as learning outcomes.

\section{Summary and research questions}

Prior research suggests that reflection or reflexivity plays a significant role in enhancing learning both at the individual and the team levels. It has also been reported that transformative or facilitative leadership has a positive impact on team reflection or reflexivity. However, one limitation of previous studies is that researchers have focused mainly on the relationship between general leadership styles and team reflexivity; no reported research has investigated leaders' reflective behaviors that facilitate team learning. That is, little is known about how leaders manage discussion and communication at meetings where work practices are a topic for the group's reflection. To clarify the effect of reflective leadership on team learning, the following research questions were proposed:

RQ1. What are the dimensions of reflective leadership?

RQ2. How are the dimensions of reflective leadership related to team learning?

In examining reflective leadership, this study focused on leaders' reflective behaviors at regular meetings in the workplace where work progress is the object of reflection and discussion. Reflection at regular meetings may involve both reflection in action and reflection on action (Schön, 1983).

\section{Methodology}

Because there has been no sufficient data derived from empirical studies, the measurement scales for reflective leadership were developed in the following preliminary research which consists of qualitative interviews, an open-ended survey and quantitative surveys. Based on the developed scales, the research questions were examined by using a quantitative survey. The research design is called "combined design" (Creswell, 1994) which attempts to mix qualitative and quantitative research 
methods. This study adopted the combined design because it was hardly possible to propose concrete hypotheses for a survey research only by reviewing the literature.

\section{Preliminary research}

Interview research. To investigate the dimensions of reflective leadership, interview research was conducted with 32 team leaders who worked in two manufacturing firms (10 middle managers in R\&D, Sales and Production departments), six hospitals (12 nursing managers) and two retail firms (10 branch managers). Subjects from different industries, job types and organizations were chosen to develop scales that can satisfy the diverse work settings. Interviewees were excellent team leaders who were recommended by the headquarters of each organization based on their skill in staff development, work process improvement and work performance. In the interviews, managers were questioned about how they promoted reflection in the team for developing staff, improving work processes and enhancing work performance. In analyzing interview data, I focused on how team leaders facilitated reflection in the meetings using a grounded theory approach (Strauss and Corbin, 1990).

Interview data were coded on the basis of a grounded theory approach, and three categories of reflective leadership were extracted: open reflection, deepening thoughts and problem-based reflection. Open reflection referred to a leader's behavior in encouraging members to speak up for their ideas or opinions. Deepening thoughts referred to a leader's behaviors to deepen members' thoughts on work progress and performance by questioning from multiple viewpoints or confirming the goals and visions. Problem-based reflection referred to a leader's behaviors in facilitating reflection on problems and failures in an effort to solve them. Analysis of the relationships among categories suggests that open reflection may constitute a basis for deepening thoughts and problem-based reflection.

Open-ended survey. To collect data on team leaders' reflective leadership from the viewpoint of team members, an open-ended survey was conducted with employees of public organizations $(n=62)$ and private firms $(n=28)$. In this survey, respondents were asked to recall team leaders who were able to balance staff development and high performance and to describe freely how those leaders promoted reflection on work progress in regular meetings.

Scale development. Based on data obtained from the interviews and the open-ended survey, a questionnaire for reflective leadership and team learning was developed. In the questionnaire, respondents were asked to recall team leaders' behaviors at regular meetings and then to answer questions about how managers promoted reflection on 
work progress (45 items) and evaluate team learning in terms of staff development, introduction of new work processes, process improvement and work performance (four items) using a five-point Likert scale ( 1 = strongly disagree, 5 = strongly agree).

Using this questionnaire, several preliminary surveys were conducted with employees of a manufacturing firm $(n=54)$, nurses at hospitals $(n=81)$ and employees of a university co-op $(n=53)$. Data were collected from employees of various types of organizations with the aim of enhancing the utility of the measures.

Procedures based partly on Churchill's (1979) paradigm were adopted for scale development. First, factor analysis (principal factors method with promax rotation) was conducted with the 45 items addressing reflective leadership behaviors. Items with loadings $<0.40$ were eliminated on all factors if the Cronbach's for a factor increased when the item was deleted. This procedure was repeated until the Cronbach's values for all factors were $>0.70$. Based on this procedure, 13 items addressing reflective leadership behaviors were grouped into three factors: open reflection (four items), problem-based reflection (five items) and goal-based reflection (four items) (Appendix). The structure of the reflective leadership behaviors was slightly different from that identified in the preliminary qualitative research. Among three dimensions, deepening thoughts was transformed into goal-based reflection. Additionally, a scale of team learning was developed based on four items: staff development, introduction of new work processes, process improvement and work performance.

The internal consistency of the constructs was evaluated using Cronbach's $\alpha$. The Cronbach's values for open reflection, problem-based reflection, goal-based reflection and team learning were 0.88, 0.94, 0.92 and 0.81, respectively. All scales met the recommended reliability coefficient of 0.70 (Nunnally, 1978).

To evaluate the convergent validity of the model constructs, a confirmatory factor analysis (CFA) with four latent learning constructs (open reflection, problem-based reflection, goal-based reflection and team learning) and a total of 17 items was conducted. The results showed that all items loaded significantly on the respective constructs ( $p<0.001$ ), and the goodness-of-fit statistics for the model were as follows: $\chi^{2}=268.63(\mathrm{df}=113, \mathrm{p}<0.001)$, comparative fit index $(\mathrm{CFI})=0.94$, root mean square error of approximation $($ RMSEA $)=0.08$ and root mean square residual $(\mathrm{RMR})=0.04$. All items loaded significantly on the assigned constructs, and the fit indices of the model were acceptable.

Convergent validities of the factors were also estimated by average variance extracted (AVE). The AVE estimate is the average amount of variance that a latent construct is able to explain in the observed variables to which it is theoretically related 
(Farrell, 2010). The average extracted variances for open reflection, problem-based reflection, goal-based reflection and team learning were 0.65, 0.76, 0.76 and 0.54, respectively. All were above the recommended 0.50 level, meaning that more than one-half of the variance observed in the items was accounted for by the respective factor.

Participants and procedure of main survey

Participants for the main survey were employees in engineering departments of two large Japanese manufactures in the automotive and electronics industries. Questionnaires were distributed to 510 employees (not in managerial positions) in 98 teams (419 employees in 70 teams at the automaker; 91 employees in 28 teams at the electronics maker) using a Web-based survey system operated by the firms. Participants were asked to respond to questionnaires on the leadership provided by their team leaders (junior managers) and on learning conditions in their teams. Because this study examined leadership from the team members' viewpoint, team leaders were excluded from the survey. In total, 507 questionnaires were considered usable after removing two with inappropriate answers. The final response rate was 99.4 per cent. The average team size (the number of respondents) was 5.91 ( $\mathrm{SD}=3.40$ ). The sample was 96.4 per cent male. This proportion is common in engineering departments of typical Japanese firms. Average job tenure was 10.08 years ( $S D=5.16)$. The distribution of participants' ages was as follows: 29 years and younger (36.8 per cent), 30-39 (56.1 per cent) and 40 years and older (7.1 per cent).

\section{Measures}

Team learning. Team learning was measured with four items addressing staff development, introduction of new work processes, process improvement and task performance. As explained above, the measures correspond to the dimensions of workplace learning (Fenwick, 2008; Zellmer-Bruhn and Gibson, 2006; Clarke, 2005). Each item measured team learning on a five-point Likert scale ( $1=$ strongly disagree, 5 $=$ strongly agree).

Open reflection. Respondents were asked to evaluate their team leaders' behaviors in terms of open reflection with four items: "Allows us to speak freely," "Elicits frank opinions by maintaining close eye contact”, "Conducts the discussion based on equality” and "Be sensitive to our thoughts". Each item measured open reflection on a five-point Likert scale (1 = strongly disagree, 5 = strongly agree).

Goal-based reflection. Respondents were asked to evaluate their team leaders' 
behaviors in terms of goal-based reflection with four items: "Reflects on our work by showing long-term vision", "Reflects on our work by identifying processes of achievement”, "Reflects on our work by confirming the purpose of our business." and

"Reflects on our work by foreseeing mid/long-term issues". Each item measured open reflection on a five-point Likert scale ( 1 = strongly disagree, 5 = strongly agree).

Problem-based reflection. Respondents were asked to evaluate their team leaders' behaviors in terms of problem-based reflection with five items: "Encourages us to identify problems at work", "Encourages us to ascertain causes of problems",

"Encourages us to generate solutions to problems", "Encourages us to think about the cause of failures" and "Encourages us to think about how to prevent failures". Each item measured problem-based reflection on a five-point Likert scale $(1=$ strongly disagree, 5 = strongly agree).

\section{Validation of the measures}

The internal consistency of the constructs was evaluated using Cronbach's $\alpha$ coefficient. The Cronbach's $\alpha$ values for problem-based reflection, goal-based reflection, open reflection and team learning were $0.93,0.92,0.89$ and 0.81 , respectively. All scales met the recommended reliability coefficient of 0.70 (Nunnally, 1978).

To evaluate the convergent validity of the model constructs, a CFA was conducted with four latent learning constructs (open reflection, problem-based reflection, goal-based reflection and team learning) and a total of 17 items. For the CFA, the disaggregated items of open reflection, problem-based reflection, goal-based reflection and team learning were used. The results show that all items loaded significantly on the respective constructs ( $\mathrm{p}<0.001)$, and the goodness-of-fit statistics for the model were as follows: $\chi^{2}=510.99(\mathrm{df}=113, \mathrm{p}<0.001)$, CFI $=0.94$, RMSEA $=0.08$ and $\mathrm{RMR}=$ 0.04 . All the items loaded significantly on the assigned constructs, and the fit indices of the model are acceptable.

Convergent validities of the factors were also estimated by AVE. The AVE values for problem-based reflection, goal-based reflection, open reflection and team learning were $0.75,0.76,0.69$ and 0.53 , respectively. All were above the recommended 0.50 level, indicating that more than one-half of the variance observed in each items was accounted for by the respective factor.

\section{Results}

Data aggregation

To assess within-team agreement, the Rwg(j) (James et al., 1984) was calculated. A 
value of 0.70 or above suggests good within-group inter-rater agreement (George, 1990). The Rwg(j) averaged 0.87 for open reflection, 0.91 for problem-based reflection, 0.87 for goal-based reflection and 0.89 for team learning. All scores were well above 0.70 , suggesting that aggregating data to the team level was justified.

Additionally, interclass correlation coefficients (ICC1 and ICC2) were calculated to assess the appropriateness of aggregating individual-level data to the team level. Between-unit variance was significant for problem-based reflection $(F(1059,23)=2.10$, $\mathrm{p}<0.001)$, goal-based reflection $(\mathrm{F}(1,059,23)=1.76, \mathrm{p}<0.001)$, open-reflection $(\mathrm{F}$ $(1,059,23)=2.47, \mathrm{p}<0.001)$ and team learning $(\mathrm{F}(1059,23)=2.06, \mathrm{p}<0.001)$. ICC1s were 0.20 for open reflection, 0.16 for problem-based reflection, 0.11 for goal-based reflection and 0.15 for team learning. ICC2 values were 0.60 for open reflection, 0.52 for problem-based reflection, 0.43 for goal-based reflection and 0.52 for team learning. ICC1 and ICC2 values were beyond the cut-off scores of 0.12 for ICC1 (James, 1982) and 0.50 for ICC2 (Bal et al., 2012), although the scores for goal-based reflection were slightly below the criterion.

Because Rwg (j) values were $>0.80$ and the average of ICC1 and ICC2 values (0.16 and 0.52 , respectively) were above the cut-off scores, aggregating the data for these four scales to the team level by taking the mean within each team was justified (Table I).

\section{Data analysis}

To see how much additional variance was explained by the independent variables after controls, hypotheses were tested with the hierarchical regression analysis. The aim for conducting this analysis was to compare the relative impact of the three reflective leadership dimensions on team learning. To rule out alternative explanations for the findings, I included the two control variables, team size and organization, which may affect the results. In the first step of these regression equations, control variables, including team size and organization ( $1=$ auto, 2 = electronic) were entered. In the second step, three dimensions of reflective leadership were added.

Table II shows the results of regression analyses. Among three dimensions, open reflection and goal-based reflection were positively related to team learning ( $\beta=0.21$, $\mathrm{p}<0.05$ ) and goal-based reflection $(\beta=0.66, \mathrm{p}<0.001$ ) as shown in Step 2. In contrast, problem-based reflection was not significantly related to team learning ( $\beta=0.05$, n.s.). The results suggest that leaders who allow members to speak up freely, and to reflect on their work processes by showing mid or long term goals or visions at regular meetings, are likely to promote learning within a team.

To investigate possible multi-collinearity, the variance inflation factor (VIF) was 
checked. The results showed that the maximum VIF was 2.88, which is below the threshold value of 10 . This indicates that no serious multi-collinearity problem was expected (Kleinbaum et al., 1988).

Table I. Descriptive statistics and correlations

\begin{tabular}{lcccccccc}
\hline \multicolumn{1}{c}{ Variables } & Mean & SD & AVE & 1 & 2 & 3 & 4 & \multicolumn{1}{c}{5} \\
\hline 1. Problem-based reflection & 3.68 & 0.48 & 0.75 & $(0.93)$ & & & & \\
2. Goal-based reflection & 3.36 & 0.48 & 0.76 & $0.69^{* *}$ & $(0.92)$ & & & \\
3. Open reflection & 3.65 & 0.55 & 0.69 & $0.64^{* *}$ & $0.60^{* *}(0.89)$ & & \\
4. Team learning & 3.43 & 0.46 & 0.53 & $0.51^{* * *}$ & $0.75^{* * *}$ & $0.56^{* * *}$ & $(0.81)$ & \\
5. Team size & 5.90 & 3.40 & - & -0.18 & 0.01 & -0.08 & 0.13 & \multicolumn{1}{c}{-} \\
6. Organization & 1.28 & 0.45 & - & $0.30^{* *}$ & -0.20 & 0.05 & -0.11 & $-0.50^{* *}$ \\
\hline
\end{tabular}

Note $: n=98 .{ }^{* *} p<0.01$. Reliabilities are shown along the diagonal in parentheses. AVE: averaged variance extracted. Organization $(1=$ Auto, 2 = Electronic)

Table II. Hierarchical regression results 


\begin{tabular}{lcc}
\hline \multirow{2}{*}{ Independent variables } & \multicolumn{2}{c}{ Team learning } \\
\cline { 2 - 3 } & Model 1 & Model 2 \\
\hline Control variable & & \\
Organization (1=auto; 2=electronic) & -0.06 & -0.03 \\
Team size & 0.11 & 0.12 \\
& & \\
Reflective leadership & & \\
Open reflection & & $0.21^{*}$ \\
Problem-based reflection & & -0.05 \\
Goal-based reflection & & $0.66{ }^{* * *}$ \\
& & \\
Adjusted $\mathrm{R}^{2}$ & 0.01 & 0.58 \\
$\Delta \mathrm{R}^{2}$ & 0.02 & 0.58 \\
$F$ & 1.02 & 28.26 \\
$d f$ & 95 & 92 \\
\hline
\end{tabular}

Note1: $\mathrm{n}=98$

Note2: * $\mathrm{p}<.05, * * \mathrm{p}<.01,{ }^{* * *} \mathrm{p}<.001$.

Note3: Maximum VIF=2.88

\section{Discussion}

Although the relationship between leadership behaviors and team reflexivity has been investigated in prior research, not a lot of studies have examined the specific leadership behaviors that facilitate reflection at the meetings within the team involving both “reflection-in-action” and “reflection-on-action” (Schön, 1983). A major contribution of this study was to clarify the types of reflective leadership behaviors and to examine their relationships with team learning.

\section{Theoretical implications}

The theoretical contribution of this study can be summarized as follows. First, the present research revealed three dimensions of reflective leadership that had not been adequately investigated previously. Open reflection creates an atmosphere to encourage 
team members to speak up for their ideas or opinions, which may ensure psychological safety (Edmondson, 1999, 2003) within the team. Problem-based reflection urges team members to discuss causes and solutions for problems or failures. This type of reflection is typically involved in a reflective process that consists of problem formulation, problem diagnosis and implementation of solutions (Heusinkveld and Reijers, 2009). Goal-based reflection encourages members to examine their work processes in terms of long-term goals, vision or the purpose of the business. The three types of reflective leadership are closely associated with one another in facilitating team learning.

Second, among the three dimensions, goal-based reflection was most strongly related to team learning. The results correspond to some research reporting a positive relationship between goal clarity and reflexivity of the team or department (Dayan and Basarir, 2010; Matsuo, 2012; Schippers et al., 2008). Schippers et al. (2008) argued that sharing a vision makes it easier for the team to reflect on whether it is still on the right path. Stam et al. (2014) also stated that vision communication, or the act of motivating followers by communicating images of the future of the collective, promoted the followers' actions aimed at making the vision a reality. Conceivably, these studies suggest that goals or visions may provide members with standards when they reflect on their work progress. That is, goals or visions can be criteria by which members appreciate and consider the meaning of their practices in the workplace (Matsuo, 2012). Meanwhile, critical reflection (Cunliffe, 2009; Reynolds, 1998) may be considered especially when team members reflect on their work progress in terms of long-term goals or visions. This study contributes to existing research by showing that leadership behaviors identifying and confirming mid- or long-term goals during reflection are closely associated with team learning.

Third, the results show that open reflection, which is closely related to facilitative leadership (Hirst et al., 2004), was positively associated with team learning, although its effect was not as substantial as goal-based reflection. This suggests that psychological safety (Edmondson, 1999, 2002) or an atmosphere where team members are able to speak up for their ideas or opinions may constitute a basis for team reflexivity. Open reflection may provide a foundation for promoting further appropriate reflections within a team. Thus, it is necessary for team leaders to initiate open reflection prior to goal-based reflection in activating learning in the team.

Finally, it is surprising that problem-based reflection had no significant relationship to team learning when all three dimensions of reflective leadership were entered in the model as predictors. This implies that problem-based reflection alone may result in instrumental learning (Mezirow, 1990) in which members are engaged in task-orientated 
problem solving, or look back on procedural assumptions guiding the problem-solving process. If we reflected only on problems or failures, this would end up leading to superficial learning. However, it should be noted that strong correlation exists between problem-based and goal-based reflection. The two types of reflection may often be combined and used for enhancing learning within teams at the review meetings.

\section{Practical implications}

Based on these theoretical implications, this study has some implications for practice. First, to promote productive reflection at a meeting, it is necessary for team leaders to understand that goal-based reflection plays a central role in reflecting on their work because it may provide members with criteria to recognize whether they are on the right track.

Second, team leaders should note that reflection on problems or failures at work does not automatically facilitate team learning. If leaders emphasize such reflection on problems or failures in terms of their mid- or long-term goals or vision, the meeting can be constructive and productive. Therefore, team leaders need to discuss about problems in the workplace with goal-based reflection at such meetings.

Third, creating an atmosphere in which members can speak up for their opinions is important to activate reflection in the team, but open reflection alone is not enough for team learning. Thus, team leaders need not only to encourage members to speak up for their ideas, reflecting on the work, but also to make them aware of the goals or vision and confirm whether team members are accomplishing these.

\section{Limitations and future research}

The limitations of this study should be acknowledged. First, because reflective leadership has not been investigated in previous studies, the research model and the measurement scales were developed based on preliminary research in this study. Thus, it is necessary to examine the reliability and validity of these scales in future research.

Second, the data were limited to the employees of engineering departments in two Japanese manufacturers. Thus, there is a possibility that national culture, characteristics of the industries and tasks traits influenced the results. To generalize the findings, future studies need to collect data from other organizations in other industries and in an international context.

Third, the measurement scales of reflective leadership do not involve those elements of critical reflection that examine the taken-for-granted context, or challenge the validity of assumptions in prior learning. Although there were some critical reflection-related 
items at the early stage of scale development process, they were eliminated through statistical analyses based on Churchill's (1979) scale development paradigm. In future research, leadership that promotes critical reflection in the teams should involve this dimension of reflective leadership.

Finally, the relationship between reflective leadership and transformational leadership remains unclear. Results of this study suggest that inspirational motivation, which is a dimension of transformational leadership, may facilitate reflection in the team. Further research should be conducted to examine how the three types of reflective leadership are associated with the dimensions of transformational leadership in enhancing team learning.

\section{Conclusion}

Previous literature has suggested that team reflection or reflexivity has a positive impact on learning and performance of the team, and that team leaders play critical roles in promoting reflection. However, little is known about how leaders specifically facilitate reflection within the teams. This study makes an important contribution by identifying three types of reflective leadership and pointing out the significance of open and goal-based reflection in enhancing team learning. The present findings suggest that teams can learn well when the leaders encourage members to speak up for their ideas or opinions, and to reflect on their work processes in terms of mid- or long-term goals or visions at the regular meetings.

\section{References}

Bal, P.M., De Jong, S.B., Jansen, P.G.W. and Bakker, A.B. (2012), “Motivating employees to work beyond retirement: a multi-level study of the role of I-deals and unit climate”, Journal of Management Studies, Vol. 49 No. 2, pp. 306-331.

Boud, D., Cressery, P. and Docherty, P. (2006), "Setting the scene for productive reflection”, in Boud, D., Cressery, P. and Docherty, P. (Eds), Productive Reflection at Work: Learning for Changing Organizations, Routledge, Oxon.

Carmeli, A., Sheaffer, Z., Binyamin, G., Reiter-Palmon, R. and Shimoni, T. (2013) "Transformational leadership and creative problem-solving: the mediating role of psychological safety and reflexivity”, Journal of Creative Behavior, Vol. 48 No. 2, pp. 115-135.

Chivers, G. (2003), "Utilising reflective practice interviews in professional development”, Journal of European Industrial Training, Vol. 27 No. 1, pp. 5-15.

Churchill, G.A. (1979), “A paradigm for developing better measures of marketing 
constructs”, Journal of Marketing Research, Vol. 16 No. 1, pp. 323-332.

Clarke, N. (2005), “Workplace learning environment and its relationship with learning outcomes in healthcare organizations", Human Resource Development International, Vol. 8 No. 2, pp. 185-205.

Clarke, N. (2006), "Why HR policies fail to support workplace learning: the complexities of policy implementation in healthcare”, International Journal of Human Resource Management, Vol. 17 No. 1, pp. 190-206.

Cressey, P., Boud, D. and Docherty, P. (2006), “The emergence of productive reflection”, in Boud, D., Cressery, P. and Docherty, P. (Eds), Productive Reflection at Work: Learning for Changing Organizations, Routledge, Oxon.

Creswell, J.W. (1994), Research Design: Qualitative and Quantitative Approaches, Sage, CA.

Cunliffe, A.L. (2009), “The philosopher leader: on relationalism, ethics and reflexivity a critical perspective to teaching leadership”, Management Learning, Vol. 40 No. 1, pp. 87-101.

Dayan, M. and Basarir, A. (2010), “Antecedents and consequences of team reflexivity in new product development projects”, Journal of Business \& Industrial Marketing, Vol. 25 No. 1, pp. 18-29.

DeFillippi, R.J. (2001), “Introduction: project-based learning, reflective practices and learning”, Management Learning, Vol. 32 No. 1, pp. 5-10.

Edmondson, A.C. (1999), "Psychological safety and learning behavior in work teams", Administrative Science Quarterly, Vol. 44 No. 2, pp. 350-383.

Edmondson, A.C. (2002), "The local and variegated nature of learning in organizations: a group-level perspective”, Organization Science, Vol. 13 No. 29, pp. 128-146.

Edmondson, A.C. (2003), "Speaking up in the operating room: how team leaders promote learning in interdisciplinary action teams”, Journal of Management Studies, Vol. 40 No. 6, pp. 1419-1452.

Enoch, O. (1997), "Leaders and followers: students developing transformational leadership through collaborator feedback”, Journal of Leadership Studies, Vol. 4 No. 3, pp. 126-143.

Farrell, A.M. (2010), "Insufficient discriminant validity: a comment on Bove, Pervan, Beatty and Shiu (2009)”, Journal of Business Research, Vol. 63 No. 3, pp. 324-327.

Fenwick, T. (2008), “Understanding relations of individual-collective learning in work: a review of research”, Management Learning, Vol. 39 No. 3, pp. 227-243.

George, J.M. (1990), "Personality, affect, and behavior in groups”, Journal of Applied 
Psychology, Vol. 75 No. 2, pp. 107-116.

Heusinkveld, S. and Reijers, H.A. (2009), "Reflections on a reflective cycle: building legitimacy in design knowledge development”, Organization Studies, Vol. 30 No. 8, pp. 865-886.

Hirst, G., Mann, L., Bain, P., Pirola-Merlo, A. and Richver, A. (2004), "Learning to lead: the development and testing of a model of leadership learning”, Leadership Quarterly, Vol. 15 No. 1, pp. 311-327.

Hoegl, M. and Parboteeah, K.P. (2006), “Team reflexivity in innovative projects”, $R \& D$ Management, Vol. 36 No. 2, pp. 113-125.

James, L.R. (1982), “Aggregation bias in estimates of perceptual agreement”, Journal of Applied Psychology, Vol. 67 No. 2, pp. 219-229.

James, L.R., Demaree, R.G. and Wolf, G. (1984), "Estimating within-group interrater reliability with and without response bias”, Journal of Applied Psychology, Vol. 69 No. 1, pp. 85-98.

Kember, D., Leung, D.Y.P., Jones, A., Loke, A.Y., McKay, J., Sinclair, K., Tse, H., Webb, C., Wong, F.K.Y., Wong, M. and Yeung, E. (2000), "Development of a questionnaire to measure the level of reflective thinking”, Assessment \& Evaluation in Higher Education, Vol. 25 No. 4, pp. 382-395.

Kleinbaum, D.G., Kupper, L.L. and Muller, K.E. (1988), Applied Regression Analysis and other Multivariable Methods, 2nd ed., PWS-KENT Publishing Company, Boston, MA.

Kolb, D.A. (1984), Experiential Learning: Experience as the Source of Learning and Development, Prentice-Hall, New Jersey.

Lee, L.T. (2008), “The effects of team reflexivity and innovativeness on new product development performance”, Industrial Management \& Data Systems, Vol. 108 No. 4, pp. 548-569.

Lombardo, M.M. and Eichinger, R.W. (2010), The Career Architect: Development Planner, 5th ed., Lominger International, Melbourne.

Marsick, V.J. and Watkins, K.E. (1990), Informal and Incidental Learning in the Workplace: International Perspectives on Adult and Continuing Education, Routledge, London.

Matsuo, M. (2012), “Leadership of learning and reflective practice: an exploratory study of nursing managers”, Management Learning, Vol. 43 No. 5, pp. 609-623.

Mezirow, J. (1990), "How critical reflection triggers transformative earning", in Mezirow, J. (Eds), Fostering Critical Reflection in Adulthood: A Guide to Transformative and Emancipatory Learning, Jossey-Bass, San Francisco. 
Nunnally, J.C. (1978), Psychometric Theory, 2nd ed., McGraw-Hill, New York, NY.

Peltier, J.W., Hay, A. and Drago, W. (2005), "The reflective learning continuum: reflecting on reflection”, Journal of Marketing Education, Vol. 27 No. 3, pp. 250-263.

Raelin, J.A. (2002), “'I don’t have time to think!’ Versus the art of reflective practice”, Reflections, Vol. 4 No. 1, pp. 66-79.

Reynolds, M. (1998), "Reflection and critical reflection in management learning", Management Learning, Vol. 29 No. 2, pp. 183-200.

Schippers, M.C., Den Hartog, D.N., Koopman, P.L. and van Knippenberg, D. (2008), "The role of transformational leadership in enhancing team reflexivity", Human Relations, Vol. 61 No. 11, pp. 1593-1616.

Schön, D.A. (1983), The Reflective Practitioner: How Professionals Think in Action, Basic Books, New York, NY.

Somech, A. (2006), "The effects of leadership style and team process on performance and innovation in functionally heterogeneous teams”, Journal of Management, Vol. 32 No. 1, pp. 132-157.

Stam, D., Lord, R.G., van Knippenberg, D. and Wisse, B. (2014), “An image of who we might become: vision communication, possible selves, and vision pursuit”, Organization Science, Vol. 25 No. 4, pp. 1172-1194.

Strauss, A. and Corbin, J. (1990), Basics of Qualitative Research, Sage, Newbury Park. van Ginkel, W., Tindale, R.S. and van Knippenberg, D. (2009), “Team reflexivity, development of shared task representations, and the use of distributed information in group decision making”, Group Dynamics: Theory, Research, and Practice, Vol. 13 No. 4, pp. 265-280.

West, M.A. (1996), "Reflexivity and work group effectiveness: a conceptual integration”, in West, M.A. (Ed.), Handbook of Work Group Psychology, John Wiley \& Sons Ltd, Chichester, pp. 555-579.

West, M.A. (2000), "Reflexivity, revolution and innovation in work teams", in Beyerlein, M.M., Johnson, D.A. and Beyerlein, S.T. (Eds), Product Development Teams, JAI Press, Stamford, CT, Vol. 5, pp. 1-29.

Yanow, D. (2009), "Ways of knowing: passionate humility and reflective practice in research and management”, American Review of Public Administration, Vol. 39 No. 6, pp. 579-601.

Zellmer-Bruhn, M. and Gibson, C. (2006), "Multinational organizational context: implications for team learning and performance”, Academy of Management Journal, Vol. 49 No. 3, pp. 501-518. 


\section{Further reading}

Avolio, B.J., Bass, B.M. and Jung, D.I. (1999), "Re-examining the components of transformational and transactional leadership using the multifactor leadership questionnaire”, Journal of Occupational and Organizational Psychology, Vol. 72 No. 4, pp. 441-462.

Gray, D.E. (2007), "Facilitating management learning: developing critical reflection through reflective tools”, Management Learning, Vol. 38 No. 5, pp. 495-517.

Judge, T.A. and Piccolo, R.F. (2004), "Transformational and transactional leadership: a meta-analytic test of their relative validity”, Journal of Applied Psychology, Vol. 89 No. 5, pp. 755-768.

Ohlsson, J. (2013), “Team learning: collective reflection processes in teacher teams”, Journal of Workplace Learning, Vol. 25 No. 5, pp. 296-309.

Sense, A.J. (2005), “Facilitating conversational learning in a project team practice”, Journal of Workplace Learning, Vol. 17 No. 3, pp. 178-193.

\section{Appendix}

The scales of reflective leadership

(1) Open reflection:

- allows us to speak freely;

- elicits frank opinions by maintaining close eye contact; and

- conducts the discussion based on equality.

(2) Goal-based reflection:

- reflects on our work by showing long-term vision;

- reflects on our work by identifying processes of achievement;

- reflects on our work by confirming the purpose of our business; and

- reflects on our work by foreseeing mid/long-term issues.

(3) Problem-based reflection:

- encourages us to identify problems at work;

- encourages us to ascertain causes of problems;

- encourages us to generate solutions to problems;

- encourages us to think about the cause of failures; and

- encourages us to think about how to prevent failures.

\section{Corresponding author}

Makoto Matsuo can be contacted at: mmatsuo@econ.hokudai.ac.jp 